\title{
Prediction of Building Orientation Effects Through Machine Learning Process of Additively Manufactured Triply Periodic Minimal Surface Scaffolds
}

Matheus Mendes da Silva de Assis ( $\nabla$ mendes.matheus@ufabc.edu.br) Federal University of the ABC, Av. dos Estados, 5001, Santo André, SP 09210-580, Brazil

Erik Gustavo del Conte

Federal University of the ABC, Av. dos Estados, 5001, Santo André, SP 09210-580, Brazil

\section{Research Article}

Keywords: Triply periodic minimal surfaces, Building Orientation, Additive Manufacturing, Material Extrusion, Design of Experiments, Machine Learning

Posted Date: March 17th, 2021

DOI: https://doi.org/10.21203/rs.3.rs-308450/v1

License: (c) (i) This work is licensed under a Creative Commons Attribution 4.0 International License. Read Full License 


\title{
PREDICTION OF BUILDING ORIENTATION EFFECTS THROUGH MACHINE LEARNING PROCESS OF ADDITIVELY MANUFACTURED TRIPLY PERIODIC MINIMAL SURFACE SCAFFOLDS
}

\author{
Matheus Mendes da Silva de Assis ${ }^{1}$ \\ Erik Gustavo del Conte ${ }^{1}$ \\ Matheus Mendes da Silva de Assis \\ mendes.matheus@ufabc.edu.br
}

${ }^{1}$ Federal University of the ABC, Av. dos Estados, 5001, Santo André, SP 09210-580, Brazil

\begin{abstract}
Triply periodic minimal surfaces (TPMS) are porous structures which can be used to create multifunctional materials for various technological applications. TPMS have a complex geometry, therefore, additive manufacturing is shown as the ideal method for their manufacturing, due to the flexibility of such method. Thus, this work aims to predict the building orientation effects through machine learning process of additively manufactured triply periodic minimal surface scaffolds. DOE (Design of experiments) was used to determine the effect of the $30^{\circ}, 60^{\circ}$ and $90^{\circ}$ angles of the $\mathrm{X}, \mathrm{Y}$ and $\mathrm{Z}$ axes of the TPMS and ANOVA (Analysis of variance) to determine the relevant statistical interactions. Subsequently, the Multi-Layer Perceptron, Random Tree and Multiple Linear Regression machine learning algorithms were used through WEKA software to predict the cost and support material consumption for each TPMS. The results showed that the cost of TPMS can vary between about 12 and 15\% according to the most expensive to the most economical building orientation. The Multiple Linear Regression algorithm obtained the best result for the cost prediction and in the support material consumption prediction the Multi-Layer Perceptron algorithm got the best.
\end{abstract}

Keywords: Triply periodic minimal surfaces. Building Orientation. Additive Manufacturing. Material Extrusion. Design of Experiments. Machine Learning. 


\section{Introduction}

Additive manufacturing has been one of the most promised technologies in industry 4.0 context. This process, which was previously used only for product models and prototype parts, according to Wong, et al. [1], nowadays it has been widely used mainly in the creation of complex parts, which would be impossible to be manufactured through conventional manufacturing process.

One of the most used additive manufacturing methods is the Material Extrusion (MEX), due to its low cost. Ngo, et al. [2], claim that in the MEX method a continuous filament of a thermoplastic polymer is used to print the materials layers in $3 \mathrm{D}$. The filament in the nozzle is heated reaching a semi-liquid state, to be extruded on the platform or on top of other layers. The thermoplasticity of the polymer filament is an essential property for this method as it allows the filaments to melt during printing and then solidify at room temperature after printing.

Considering that, process planning is essential when the objective is to reduce costs and get the best result. One of the steps in the additive manufacturing planning process is the building orientation, which consists in the definition of part angles orientation according to the $\mathrm{X}, \mathrm{Y}$ and $\mathrm{Z}$ axes. According to Allen and Dutta [3] the building orientation is one of the firsts and most influential steps in the additive manufacturing process, because through this orientation, the manufacturing process time and the number of the layers will be defined. Furthermore, Croccolo, et al. [4] mention that the building orientation can make significantly influence in the product fatigue resistance, preventing failures, optimizing the general strength and expanding the material properties compared to conventional manufacturing.

Machine learning is another technology that has been widely disseminated, this technology aims to predict parameters through a sample data [5]. We can use machine learning in additive manufacturing to predict, for example, the product cost or the amount of material used in the manufacturing process.

Gradually machine learning has been related in additive manufacturing process in different ways. Mohamed et al. [6, 7] used machine learning to optimize process parameters, improving the product viscoelastic responses and predicting the product dynamic modulus elasticity. Sood et al. [8] used machine learning to optimize the parameters and improve mechanical strength of the product. Jiang et al. [9], were able to minimize the support material wasting through the use of machine learning in MEX additive manufacturing. Thus, it is clear that there are several different ways to apply machine learning in the additive manufacturing process. 
Triply periodic minimal surface (TPMS) are porous structures which can be used to create multifunctional materials for various technological applications. These structures are infinitely extensible and continuous surfaces which has two intertwined regions $[10,11]$.

Regarding the triply periodic minimal surface produced through additive manufacturing, the literature shows several studies using this technology. Maconachie et al. [12], carried out a study investigating the effects of the layers thickness on the manufacturing capacity and on the mechanical properties of the Gyroid TPMS, manufactured using the MEX method. De Aquino et al. [13] investigated the effect of the loading direction combined with TPMS scaffold type on the mechanical properties of scaffolds manufactured by MEX. Karimipour-Fard et al. [14] studied the effect of design, porosity, and biodegradation on the mechanical and morphological properties of TPMS scaffolds. In the Moleirinho et al. [15] study, columns were built based on the Gyroid geometry using the MEX method with two different ligands: diethylaminoethyl (DEAE) and hydroxyapatite for the purification of oncolytic adenovirus and lentiviral vectors.

Thus, the general objective of this study is to predict the building orientation effects through machine learning process of additively manufactured triply periodic minimal surface scaffolds. A design of experiments (DOE) was used to analyze the building orientation effect in the TPMS cost, and the machine learning to predict parameters from DOE, comparing the effectiveness of the machine learning algorithms.

\section{Materials and methods}

Based on previous work by De Aquino et al. [13], were selected three triply periodic minimal surfaces: Diamond, Gyroid and Primitive. The TPMS parameters are shown in Table 1 and the TPMS can be seen in Figure 1:

Table 1 - TPMS Parameters

\begin{tabular}{|l|l|}
\hline PARAMETERS & DATA \\
\hline Geometry & Cubic \\
\hline Dimensions & $30 \times 30 \times 30 \mathrm{~mm}$ \\
\hline Number of cells & $3 \times 3 \times 3$ \\
\hline Surface Type & Primitive, Gyroid or Diamond \\
\hline Volume Fraction & 0,3 \\
\hline
\end{tabular}

Source: Author 


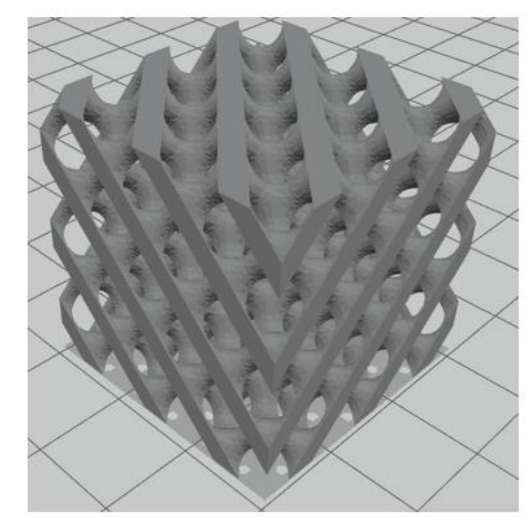

DIAMOND

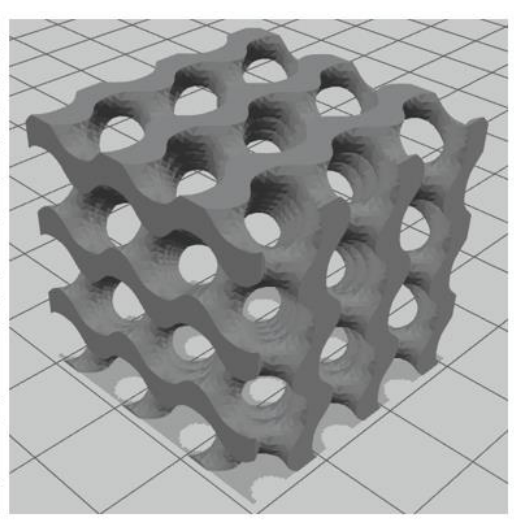

GYROID

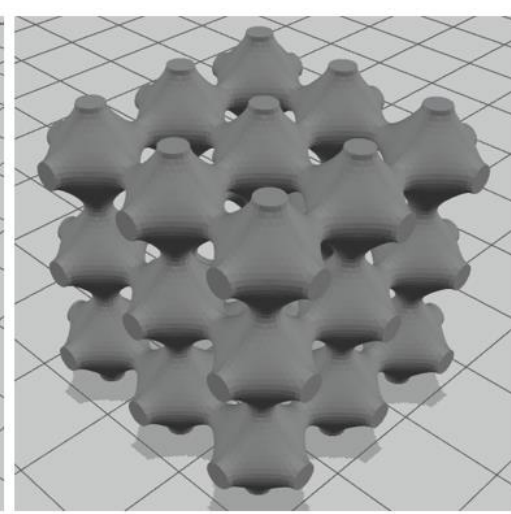

PRIMITIVE

Figure 1 - TPMS Source: Author

The simulation with each TPMS and building orientation angles were performed using GrabCad Print software version 1.37.15. For each simulation, the following variables were estimated: material consumption in $\mathrm{cm}^{3}$, support material consumption in $\mathrm{cm}^{3}$ and the production time in hours. The printer selected for the simulation was the Stratasys uPrint SE and the material set up was the ABS P430XL.

Through previous analyzes and a statistical software, we could determine the following variables: $30^{\circ}, 60^{\circ}$ and $90^{\circ}$ angles of the $\mathrm{X}, \mathrm{Y}$ and $\mathrm{Z}$ axes of each of the three TPMS. Then for each one, 27 combinations were established, totaling 81 experimental conditions, used in design of experiment (DOE). Table 2 shows the variables used in the experiment.

Table 2 - Variables

\begin{tabular}{|l|l|l|l|}
\hline Control Variable & $\mathbf{1}^{\text {st }}$ level & $\mathbf{2}^{\text {nd }}$ level & $\mathbf{3}^{\text {rd }}$ level \\
\hline TPMS & Diamond & Gyroid & Primitive \\
\hline Axis X & $30^{\circ}$ & $60^{\circ}$ & $90^{\circ}$ \\
\hline Axis Y & $30^{\circ}$ & $60^{\circ}$ & $90^{\circ}$ \\
\hline Axis Z & $30^{\circ}$ & $60^{\circ}$ & $90^{\circ}$ \\
\hline
\end{tabular}

Source: Author

Using these data, the product cost was estimated based on the absorption costing, it is possible to observe the application of the costing in table 3, through the categories: material, production, printer, labor and total costs.

Table 3 - TPMS costs

\begin{tabular}{|c|l|r|}
\hline \multirow{5}{*}{ Material } & Material Value & $\$ 0,20 / \mathrm{cm}^{3}$ \\
\cline { 2 - 3 } & Support Material Value & $\$ 0,20 / \mathrm{cm}^{3}$ \\
\hline \multirow{5}{*}{ Production } & Kwh price & $\$ 0,15$ \\
\cline { 2 - 3 } & Printer consumption & $1610 \mathrm{~W}$ \\
\cline { 2 - 3 } & Maintenance value per minute & $\$ 0,01$ \\
\cline { 2 - 3 } & Annual Maintenance Value & $\$ 1.421,20$ \\
\cline { 2 - 3 } & Depreciation value per minute & $\$ 0,20$ \\
\hline
\end{tabular}




\begin{tabular}{|c|l|r|} 
& Production minutes in service life & $720000 \mathrm{~min}$ \\
\hline \multirow{5}{*}{ Printer } & Printer value & $\$ 14.212,00$ \\
\cline { 2 - 3 } & Work hours & 8 horas \\
\cline { 2 - 3 } & Work days in a month & 25 days \\
\hline \multirow{5}{*}{ Tabor } & Average Monthly Salary & $\$ 3.000,00$ \\
\cline { 2 - 3 } & Labor charges & $40 \%$ \\
\cline { 2 - 3 } & Total Labor Cost & $\$ 4.200,00$ \\
\hline \multirow{5}{*}{} & Material used & $\$ 0,20 / \mathrm{cm}^{3}$ \\
\cline { 2 - 3 } & Support Material used & $\$ 0,20 / \mathrm{cm}^{3}$ \\
\cline { 2 - 3 } & Electricity & $\$ 0,004 / \mathrm{min}$ \\
\cline { 2 - 3 } & Depreciation & $\$ 0,20 / \mathrm{min}$ \\
\cline { 2 - 3 } & Maintenance & $\$ 0,01 / \mathrm{min}$ \\
\cline { 2 - 3 } & Labor & $\$ 0,35 / \mathrm{min}$ \\
\cline { 2 - 3 } & Total Costs & Sum \\
\hline
\end{tabular}

Source: Author

The material was price was got from a Stratasys supplier in December 2020. Both the model material and the support material have the same price that is equivalent to $\$ 0,20 / \mathrm{cm}^{3}$.

Regarding to the production, the energy price per $\mathrm{kWh}$ was based on an average of the US kWh value in December 2020. The machine consumption was based on the printer user's manual. The annual maintenance value was established as a $10 \%$ of the printer value. The depreciation and the service life time were based on 5 years.

In the machine category, considering that the printer is no longer being produced, the price was based on a used printer of the same model. In labor, the salary was based in a Google research about the American 3D machine operator and the USA labor charges reach about 40\%. And in the total costs, there are the sum of all these costs, estimating the total cost of each product produced.

Finally, we carried out the cost values and support material consumption prediction, through the machine learning algorithms application using the WEKA software. We used the following algorithms: Random Tree, Multilayer Perceptron and Multiple Linear Regression from WEKA. For all the experiments, the training set method was used. In the Multilayer Perceptron settings, 500 training times were determined, and in the other two algorithms, the standard settings were used.

\section{Results}

\subsection{Design of Experiments (DOE)}

According to analysis of variance (ANOVA), Montgomery and Runger [16] affirms that $\mathrm{DF}$ are the degrees of freedom, SS is the sum of squares, the F value is the division of the mean 
of the squares by the mean of the squares of the error, and the P value determines whether the factors have statistical significance.

Table 4 shows the analysis of variance (ANOVA) that sought to identify the interaction between TPMS and the $\mathrm{X}, \mathrm{Y}$ and $\mathrm{Z}$ axes.

Table 4 - Analysis of variance (ANOVA)

\begin{tabular}{|l|r|r|r|r|}
\hline \multicolumn{1}{|c|}{ Source } & DF & \multicolumn{1}{c|}{ SS } & F-Value & P-Value \\
\hline Model & 56 & 85787,1 & 102,42 & 0 \\
\hline Linear & 8 & 84526,6 & 706,39 & 0 \\
\hline TPMS & 2 & 81943,1 & 2739,19 & 0 \\
\hline X Axis & 2 & 21,1 & 0,7 & 0,505 \\
\hline Y Axis & 2 & 2526,3 & 84,45 & 0 \\
\hline Z Axis & 2 & 36,2 & 1,21 & 0,316 \\
\hline 2-Way Interactions & 24 & 1178,8 & 3,28 & 0,003 \\
\hline TPMS*X Axis & 4 & 218,1 & 3,65 & 0,019 \\
\hline TPMS *Y Axis & 4 & 860,5 & 14,38 & 0 \\
\hline TPMS *Z Axis & 4 & 15,9 & 0,27 & 0,897 \\
\hline X Axis*Y Axis & 4 & 73 & 1,22 & 0,328 \\
\hline X Axis*Z Axis & 4 & 4,7 & 0,08 & 0,988 \\
\hline Y Axis*Z Axis & 4 & 6,5 & 0,11 & 0,978 \\
\hline 3-Way Interactions & 24 & 81,6 & 0,23 & 1 \\
\hline TPMS*X Axis*Z Axis & 8 & 20,8 & 0,17 & 0,993 \\
\hline TPMS *Y Axis*Z Axis & 8 & 21,6 & 0,18 & 0,991 \\
\hline X Axis*Y Axis*Z Axis & 8 & 39,2 & 0,33 & 0,947 \\
\hline Error & 24 & 359 & & \\
\hline Total & 80 & 86146 & & \\
\hline
\end{tabular}

Source: Author

The significance level used in $\mathrm{P}$ Value is 0.05 , thus, the cost analysis of variance shows that the TPMS and the $\mathrm{Y}$ axis are significant for the cost because it has a value less than 0.05 , but the $\mathrm{X}$ and $\mathrm{Z}$ axis have no significance due to their higher values. The 2-way interactions express that TPMS and $\mathrm{X}$ axis and TPMS and $\mathrm{Y}$ axis are significant. Considering that the $\mathrm{X}$ and $\mathrm{Y}$ axes have no significance between them, the 3 and 4-way interaction will also not be significant, because it demonstrates that the factors are independents [17]

\subsubsection{Main effects plot}

In the main effects plot in figure 2, are shown only the significant parameters, which are, TPMS and Y axis, so in the TPMS factor it is understood that the order from highest to lowest cost is, Diamond, Gyroid and Primitive. In the $\mathrm{Y}$ axis, it is possible to understand that the $60^{\circ}$ angle has a tendency to obtain the highest cost, and the $90^{\circ}$ angle tends to obtain a lower cost. 


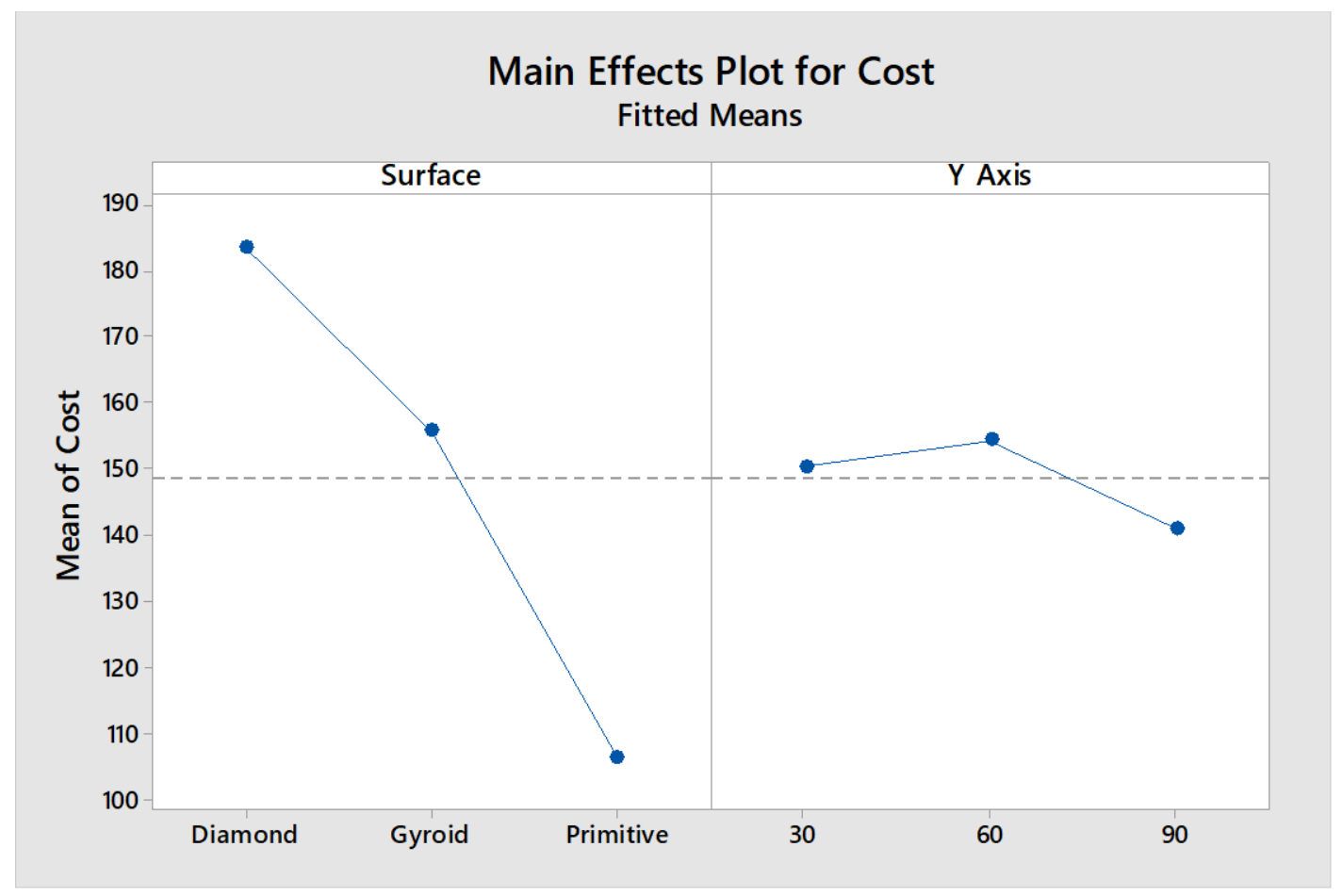

Figure 2 - Main effects plot Source: Minitab Analysis Result

\subsubsection{Interaction plot}

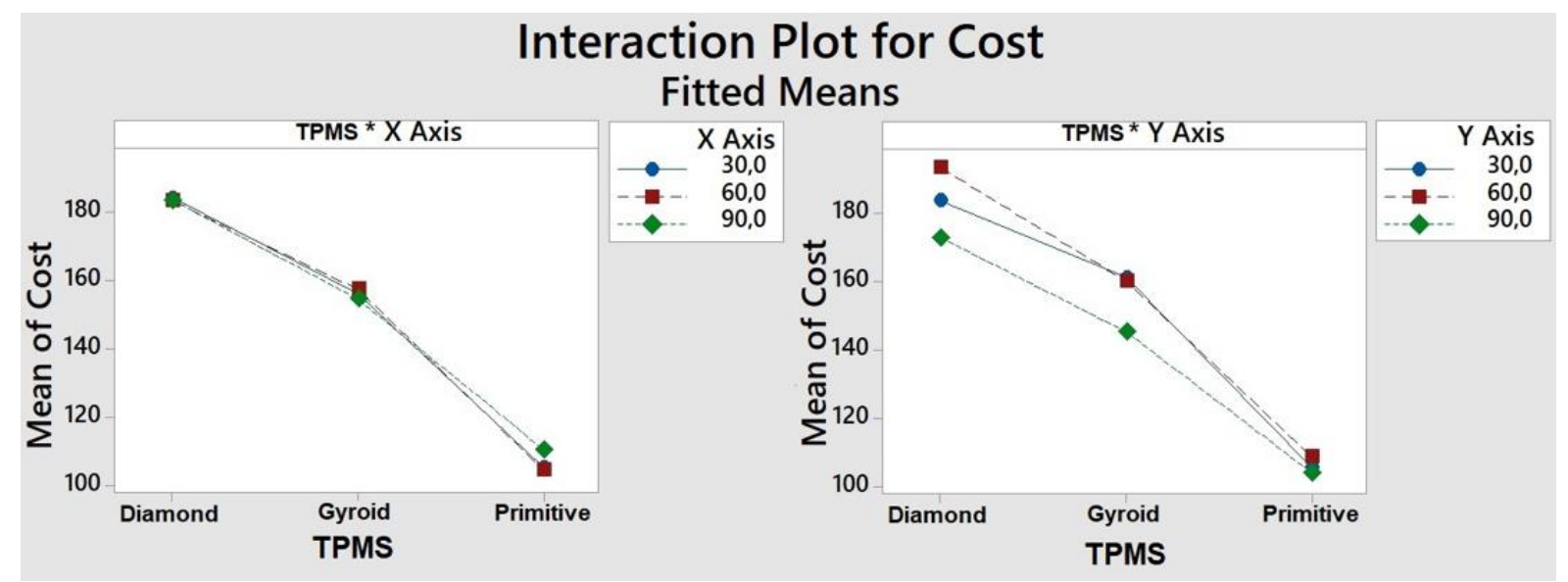

Figure 3 - Interaction plot Source: Minitab Analysis Result

As previously discussed in the analysis of variance (ANOVA), there was only an interaction of the TPMS and X axis and TPMS and Y axis, as shown in figure 3. This occurred due to the geometric shape of each type of TPMS.

\subsubsection{Effects on TPMS Cost}

According to each set of angles in the building orientation, it was observed that several angles contribute to the higher or lower materials consumption, as well as the longer or shorter production time affecting the cost. To illustrate, in table 5 it is possible to observe the highest and lowest costs of each TPMS and the percentage difference between the highest and lowest. 
Table 5 - Effects on TPMS cost

\begin{tabular}{|c|c|c|c|c|c|}
\hline \multicolumn{6}{|c|}{ DIAMOND } \\
\hline \multirow{3}{*}{ Higher Cost } & Axis & Material: & $7,857 \mathrm{~cm}^{3}$ & \multirow{3}{*}{$\begin{array}{c}\text { Cost: } \\
\$ 194,51\end{array}$} & \multirow{6}{*}{$\begin{array}{c}\text { Percentage } \\
15,08 \%\end{array}$} \\
\hline & \multirow{2}{*}{$\begin{array}{c}X=30^{\circ} \mid Y=60^{\circ} \\
\mid Z=30^{\circ}\end{array}$} & $\begin{array}{l}\text { Support } \\
\text { Material: }\end{array}$ & $14,297 \mathrm{~cm}^{3}$ & & \\
\hline & & Time: & $5: 37 \mathrm{~h}$ & & \\
\hline \multirow{3}{*}{$\begin{array}{c}\text { Lowest } \\
\text { Cost }\end{array}$} & \multirow{3}{*}{$\begin{array}{c}X=30^{\circ} \mid Y=90^{\circ} \\
\mid Z=60^{\circ}\end{array}$} & Material: & $8,144 \mathrm{~cm}^{3}$ & \multirow{3}{*}{ Cost: $\$ 165,17$} & \\
\hline & & \begin{tabular}{|l|} 
Support \\
Material:
\end{tabular} & $11,166 \mathrm{~cm}^{3}$ & & \\
\hline & & Time: & $4: 446 \mathrm{~h}$ & & \\
\hline \multicolumn{6}{|c|}{ GYROID } \\
\hline \multirow{3}{*}{ Higher Cost } & Axis & Material: & $8,044 \mathrm{~cm}^{3}$ & \multirow{3}{*}{$\begin{array}{c}\text { Cost: } \\
\$ 154,73\end{array}$} & \multirow{6}{*}{$\begin{array}{c}\text { Percentage } \\
15,71 \%\end{array}$} \\
\hline & $X=60^{\circ} \mid Y=60^{\circ}$ & $\begin{array}{l}\text { Support } \\
\text { Material: }\end{array}$ & $12,638 \mathrm{~cm}^{3}$ & & \\
\hline & & Time: & $4: 27 \mathrm{~h}$ & & \\
\hline \multirow{3}{*}{$\begin{array}{c}\text { Lowest } \\
\text { Cost }\end{array}$} & \multirow{3}{*}{$\begin{array}{c}X=30^{\circ} \mid Y=90^{\circ} \\
\mid Z=30^{\circ}\end{array}$} & Material: & $8,003 \mathrm{~cm}^{3}$ & \multirow{3}{*}{$\begin{array}{l}\text { Cost: } \\
\$ 130,41\end{array}$} & \\
\hline & & \begin{tabular}{|l|} 
Support \\
Material:
\end{tabular} & $9,512 \mathrm{~cm}^{3}$ & & \\
\hline & & Time: & $3: 45 \mathrm{~h}$ & & \\
\hline \multicolumn{6}{|c|}{ PRIMITIVE } \\
\hline \multirow{3}{*}{ Higher Cost } & Axis & Material: & $7,669 \mathrm{~cm}^{3}$ & \multirow{3}{*}{$\begin{array}{c}\text { Cost: } \\
\$ 101,29\end{array}$} & \multirow{6}{*}{$\begin{array}{c}\text { Percentage } \\
12,50 \%\end{array}$} \\
\hline & $\mathrm{X}=90^{\circ} \mid \mathrm{Y}=60^{\circ}$ & $\begin{array}{l}\text { Support } \\
\text { Material: }\end{array}$ & $8,095 \mathrm{~cm}^{3}$ & & \\
\hline & $Z=30^{\circ}$ & Time: & $2: 54 \mathrm{~h}$ & & \\
\hline \multirow{3}{*}{$\begin{array}{c}\text { Lowest } \\
\text { Cost }\end{array}$} & \multirow{3}{*}{$\begin{array}{c}X=60^{\circ} \mid Y=30^{\circ} \\
\mid Z=90^{\circ}\end{array}$} & Material: & $7,709 \mathrm{~cm}^{3}$ & \multirow{3}{*}{$\begin{array}{l}\text { Cost: } \\
\$ 88,62\end{array}$} & \\
\hline & & \begin{tabular}{|l|} 
Support \\
Material:
\end{tabular} & $6,73 \mathrm{~cm}^{3}$ & & \\
\hline & & Time: & $2: 32 \mathrm{~h}$ & & \\
\hline
\end{tabular}

Source: Author

We can see that there is a percentage variability about $12 \%$ to $15 \%$ from the highest to the lowest results. In table 6 , we can observe the result of the building orientation on each of the highest and lowest cost TPMS, respectively.

Table 6 - Optimized results

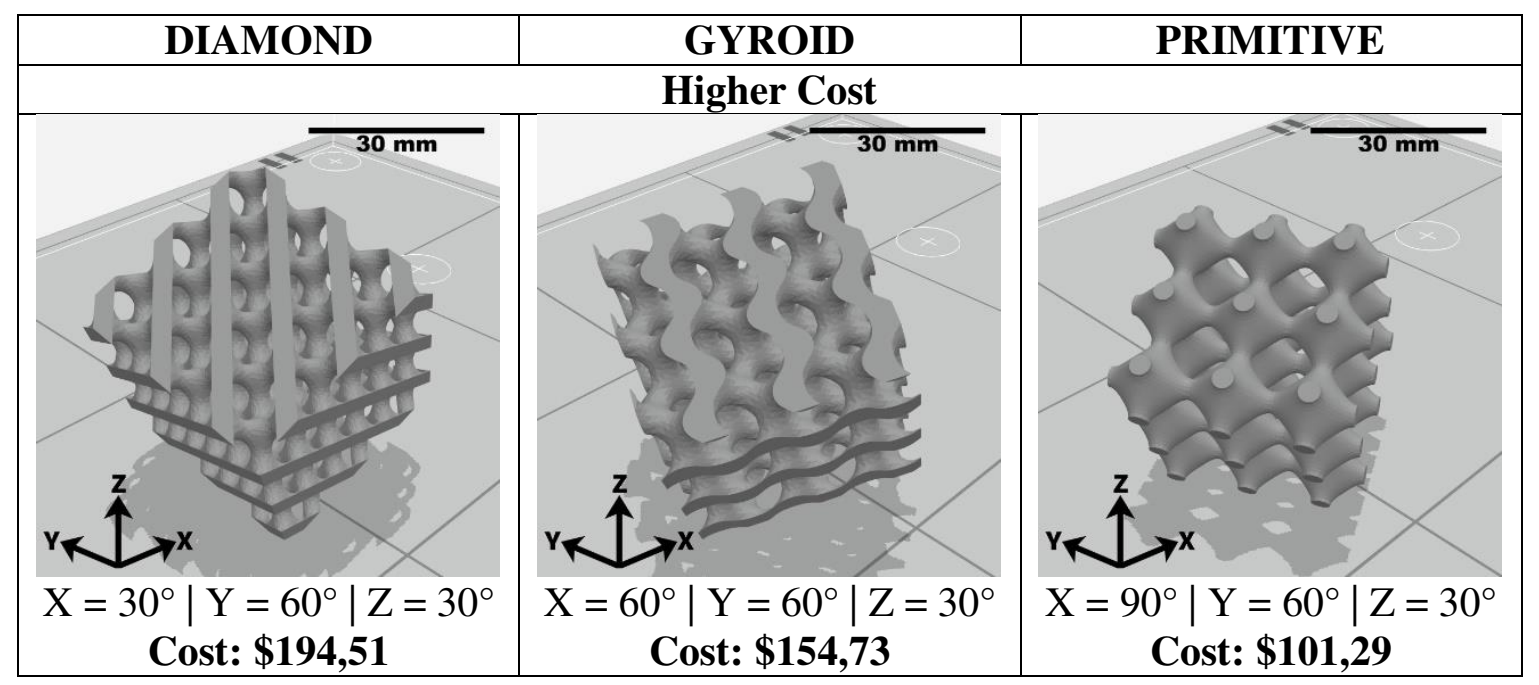




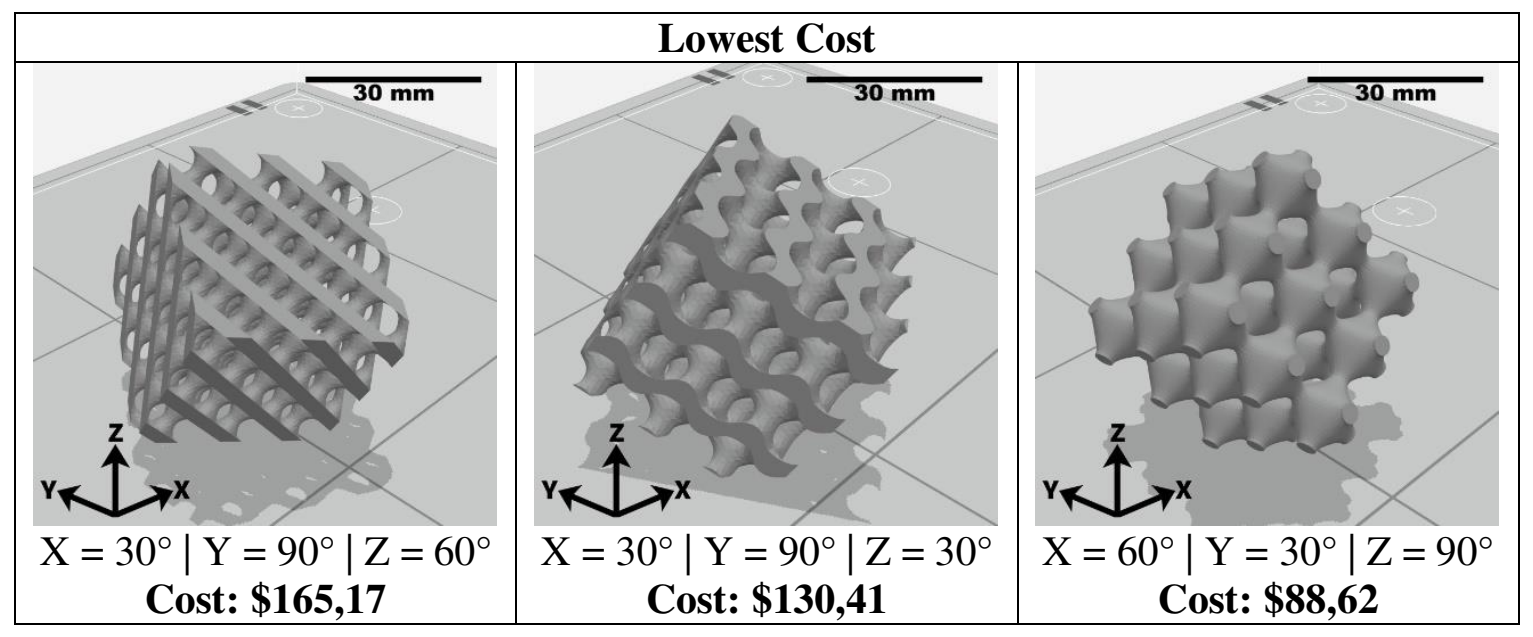

Source: Author

The standard building orientation according to the software are both $90^{\circ}$ axes, therefore, following the standard determined by the software, the TPMS costs are: Diamond $\$ 166,85$; Gyroid $\$ 130,41$; and Primitive $\$ 93,50$.

We proceeded to the second stage of the study, which has the objective, to predict the values related to the cost and support material consumption through machine learning algorithms with the WEKA software.

\subsection{Prediction through the machine learning algorithms}

The algorithms application, brought the following results:

\subsubsection{Multi-Layer Perceptron}

First, we applied the Multi-layer Perceptron algorithm, a neural network algorithm, table 7 shows the result for the prediction of cost and support material.

Table 7 - Multi-Layer Perceptron results

\begin{tabular}{|c|c|c|c|}
\hline \multicolumn{4}{|c|}{ MULTI-LAYER PERCEPTRON } \\
\hline \multicolumn{2}{|l|}{ Cost } & \multicolumn{2}{|l|}{ Support Material } \\
\hline Correlation Coefficient: & 1 & Correlation Coefficient: & 0,9983 \\
\hline Mean Absolute error: & 0,1594 & Mean Absolute error: & 0,178 \\
\hline Root mean squared error: & 0,1955 & Root mean squared error: & 0,2213 \\
\hline Relative absolute error: & $0,55 \%$ & Relative absolute error: & $7,44 \%$ \\
\hline Root relative squared error: & $0,60 \%$ & Root relative squared error: & $8,35 \%$ \\
\hline
\end{tabular}

Source: Author

Therefore, for the cost prediction the algorithm achieved an excellent correlation coefficient of 1 with a mean absolute error of only 0,1594. For the support material prediction, a correlation coefficient of 0,9983 was reached with a mean absolute error of 0,178 . The figures below show the neural networks created by the algorithm to predict cost and support material. 
Figure 4 shows the application of the multilayer perceptron algorithm using 5 nodes for cost prediction.

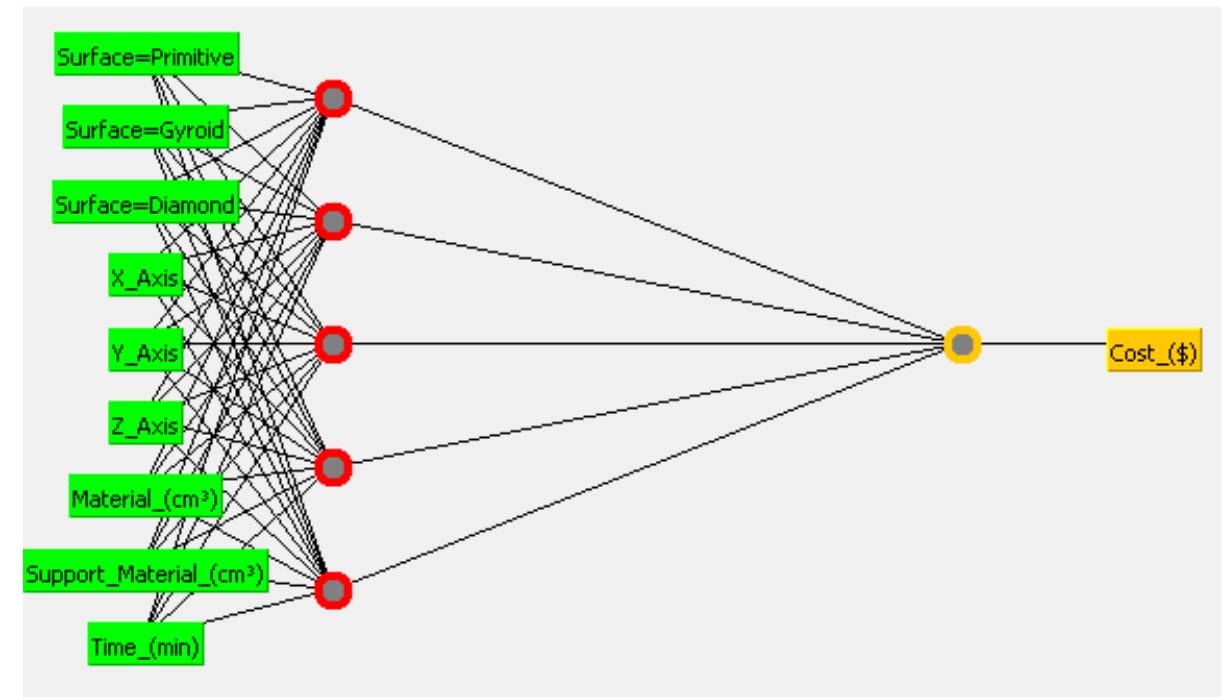

Figure 4: Neural networks created by the Multilayer Perceptron algorithm for cost Source:

Author

Figure 5 evidences the multilayer perceptron algorithm using 5 nodes for the support material prediction.

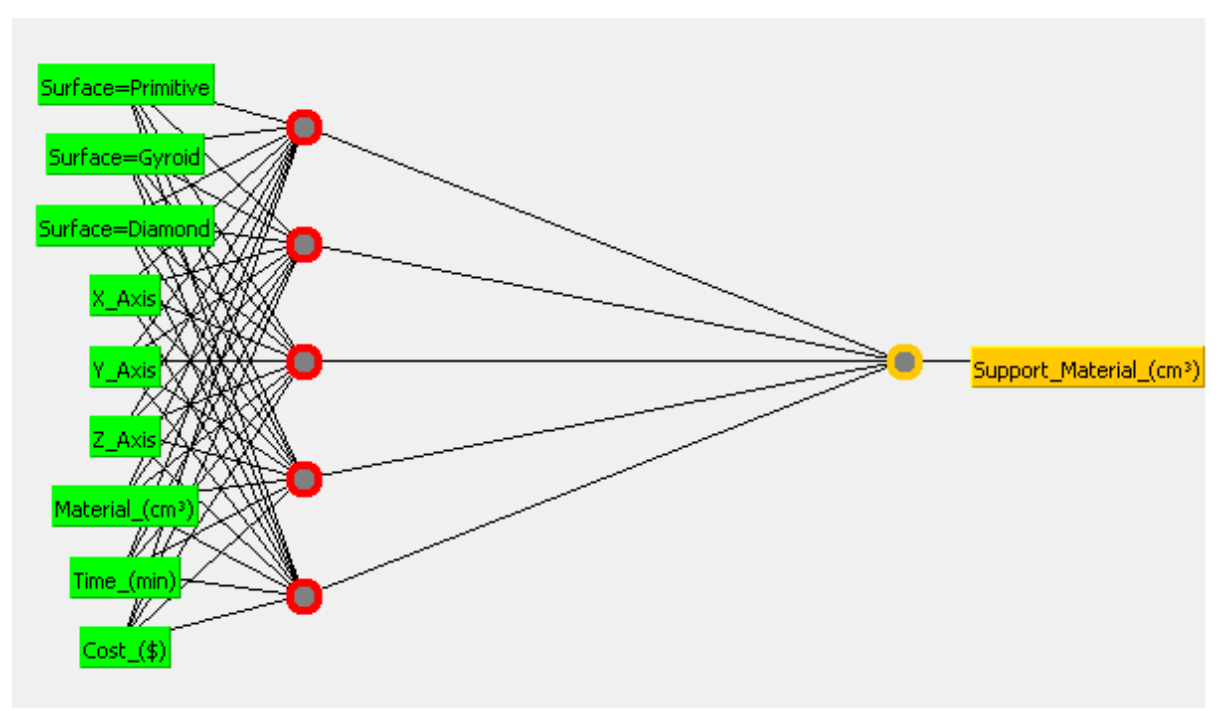

Figure 5: Neural networks created by the Multilayer Perceptron algorithm for support material Source: Author

\subsubsection{Random Tree}

Subsequently, the Radom Tree algorithm was applied to predict the cost and the support material consumption, this algorithm is based in decision trees.

As we can see in Table 8, the Random Tree algorithm proved to be very efficient for 
the cost prediction with a correlation coefficient of 0,996 , and with a mean absolute error of only 2,2025 . In the support material prediction, the algorithm reached a correlation coefficient of 0,9862 , with a mean absolute error of 0,2902 .

Table 8 - Random Tree results

\begin{tabular}{|l|r|l|r|}
\hline \multicolumn{5}{|c|}{ RANDOM TREE } \\
\hline \multicolumn{1}{|c|}{ Cost } & & \multicolumn{2}{c|}{ Support Material } \\
\hline Correlation Coefficient: & 0,996 & Correlation Coefficient: & 0,9862 \\
\hline Mean Absolute error: & 2,2025 & Mean Absolute error: & 0,2902 \\
\hline Root mean squared error: & 2,896 & Root mean squared error: & 0,44 \\
\hline Relative absolute error: & $7,666 \%$ & Relative absolute error: & $11,9998 \%$ \\
\hline Root relative squared error: & $8,8803 \%$ & Root relative squared error: & $16,4221 \%$ \\
\hline
\end{tabular}

Source: Author

Figure 6 and 7 shows the decision tree created by the Random Tree algorithm. For cost prediction in figure 6 it is possible to observe 8 decision nodes and 11 terminal nodes starting from the root node. For the support material prediction in figure 7, 9 decision nodes and 11 terminal nodes starting from the root node can be seen. 


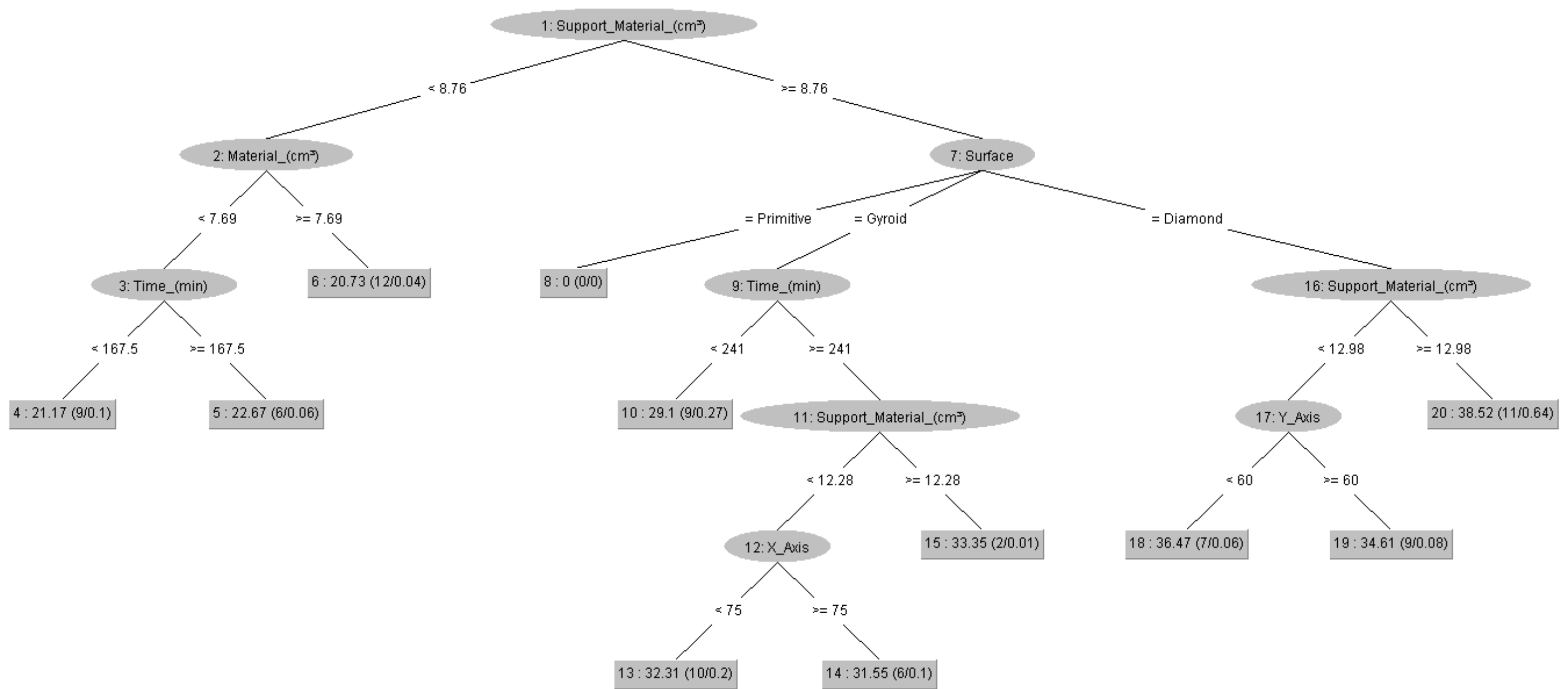

Figure 6: Decision tree from Random Tree algorithm to predict cost Source: WEKA 


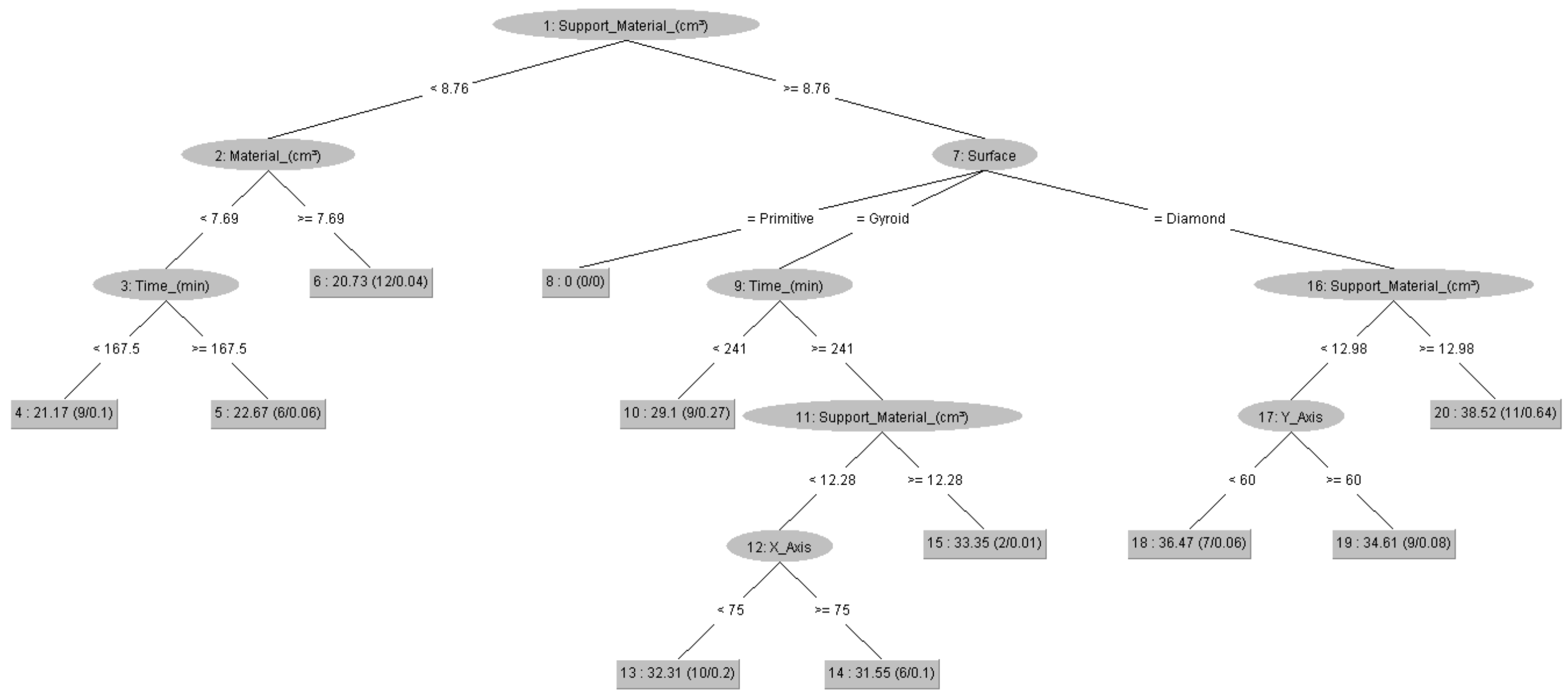

Figure 7: Decision tree from Random Tree algorithm to predict support material Source: WEKA 


\subsubsection{Multiple Linear Regression}

Finally, the Multiple Linear Regression algorithm was used, this is a multiple linear regression algorithm. The algorithm reached the correlation coefficient of 1 and a mean absolute error of 0 , proving that the algorithm worked perfectly in the cost prediction. In the support material prediction, a correlation coefficient of 0.9896 and a mean absolute error of 0.3017 were obtained.

Table 9: Multiple linear Regression results

\begin{tabular}{|l|r|l|r|}
\hline \multicolumn{4}{|c|}{ MULTIPLE LINEAR REGRESSION } \\
\hline \multicolumn{1}{|c|}{ Cost } & & \multicolumn{2}{c|}{ Support Material } \\
\hline Correlation Coefficient: & 1 & Correlation Coefficient: & 0,9896 \\
\hline Mean Absolute error: & 0 & Mean Absolute error: & 0,3017 \\
\hline Root mean squared error: & 0 & Root mean squared error: & 0,3813 \\
\hline Relative absolute error: & $0,00 \%$ & Relative absolute error: & $12,62 \%$ \\
\hline Root relative squared error: & $0,00 \%$ & Root relative squared error: & $14,38 \%$ \\
\hline
\end{tabular}

Source: Author

\section{Discussion}

Comparing to design of experiments (DOE) method, some studies have shown good results applying this method to obtain the best building orientation to the additive manufacturing. Srivastava et al. [18] conducted a study which aimed to optimize the materials consumption and improve the production time using the MEX method. That study used DOE to analyze the building orientation and the layer resolution. The building orientation definition was $0^{\circ}, 15^{\circ}$ and $30^{\circ}$ for the $\mathrm{X}$ and $\mathrm{Y}$ axes and the layer resolution was $0.1778 \mathrm{~mm}, 0.254 \mathrm{~mm}$ and $0.3302 \mathrm{~mm}$. The result showed that for a better material consumption optimization and the production time improvement, the building orientation on both axes must be at $0^{\circ}$ and the layer resolution at $0.254 \mathrm{~mm}$. That study shows a similar approach as we used in the present study, with a similar objective of reducing material consumption and production time and consequently in cost.

In the study by Mwema and Akinlabi [19], DOE was used to optimize the roughness using also the MEX method, in the study they used the $0^{\circ}, 15^{\circ}, 30^{\circ}, 45^{\circ}, 60^{\circ}$ e $90^{\circ}$ angles on the $\mathrm{X}$ and $\mathrm{Y}$ axes for the building orientation, and $0.1 \mathrm{~mm}, 0.2 \mathrm{~mm}$ and $0.3 \mathrm{~mm}$ for the layer resolution. Finally, the study concluded that the layer resolution of $0.1 \mathrm{~mm}$ and the $0^{\circ}$ and $90^{\circ}$ orientations on the $\mathrm{X}$ and $\mathrm{Y}$ axes, respectively, obtained the smallest roughness. When comparing these results to the present work, it is clear that the experimental method was similar, demonstrating that it is possible to not only optimize costs, but also the product roughness. 
When using the DOE for determining parameters and the WEKA software for predicting the best parameters, the study by Molero et al. [20] has an approach similar to that used in the present study. That study aimed to predict the roughness for a specific product manufactured by the MEX method, the authors defined some parameters as the layer resolution and the flow, these parameters were tested in two fixed orientations, $\mathrm{X}=0^{\circ}$ and $\mathrm{Y}=90^{\circ}$ and $\mathrm{X}$ $=0^{\circ}$ and $\mathrm{Z}=90^{\circ}$. The DOE experiment was carried out and through WEKA some algorithms including Random Tree, Multilayer Perceptron, Logistic Model Trees and J48 were used for the roughness prediction. The work results demonstrated that the layers resolution and the flow were the most important parameters for the best product finishing in both predefined orientations. The J48 algorithm obtained the best result in the roughness prediction, however Multilayer Perceptron and Logistic Model Trees, obtained better results in cross-validation tests. Despite of that study parameters are different from the present study parameters, it is possible to understand that this approach is efficient in the planning process, and in the patterns prediction in additive manufacturing.

In the study by Huynh et al. [21], the objective was to predict the product mechanical properties also using the MEX method. In that study, print speed, layer resolution and extrusion temperature were used as parameters, the DOE was performed and, the results were submitted to the WEKA linear regression algorithm, which obtained a correlation coefficient of 0.8015 and a mean absolute error of 22.6505 in the prediction, demonstrating that the ideal parameters for the best mechanical properties are: printing speed $=48 \mathrm{~mm} / \mathrm{s}$, layer resolution $=0.15 \mathrm{~mm}$ and extrusion temperature $=220^{\circ} \mathrm{C}$. This study corroborates about the linear regression algorithm effectiveness, proving to be the most efficient algorithm in the present study obtaining 1 of correlation coefficient and 0 of mean absolute error for cost prediction and 0,9896 of correlation coefficient and 0,3017 of mean absolute error predicting support material.

Following this approach, Barrios and Romero [22] also predicted the roughness, the parameters used were the layer resolution, extrusion temperature, print speed and acceleration and flow. After the DOE elaboration, the data were submitted to the J48, Random Forest and Random Tree algorithms, after the analysis, Random Tree reached the best results obtaining a correlation coefficient of 0.8667 and a mean absolute error of 0,13 , showing that the most influential parameters for the best roughness are the layer resolution, printing acceleration and flow. In the present study Random Tree algorithm obtained 0,996 in the correlation coefficient for cost prediction and 0,9862 for support material prediction. And the means absolute error was 2,2025 for cost and 0,2902 for support material. These results show the Random Tree algorithm proved to be very effective, with a high percentage of correct answers and a low mean 
percentage of error in both studies.

Through these studies, it is understood that the design of experiments (DOE) approach and the algorithms predictions in the additive manufacturing planning process is a really effective method, however, until then, similar studies using triply periodic minimal surface are not found in the literature, demonstrating that this is a unique study, so, it is necessary to carry out other experimental approaches about it to obtain more data.

\section{Conclusion}

This work aimed to present prediction of building orientation effects through machine learning process of additively manufactured triply periodic minimal surface scaffolds. This objective was concluded through the DOE method and the use of algorithms present in WEKA software.

it was possible to conclude that the DOE method was very effective, demonstrating the interactions that are really relevant to the work, and it was possible to see that with a good process planning, it is possible to save a lot with material cost. For the Diamond type, the ideal orientation setting is $\mathrm{X}=30^{\circ}, \mathrm{Y}=90^{\circ}$ and $\mathrm{Z}=60^{\circ}$ with a cost of $\$ 165,17$, being $15,08 \%$ less than the highest cost orientation. For the Gyroid type, the angles $X=30^{\circ}, Y=90^{\circ}$ and $Z=30^{\circ}$ obtained a cost of $\$ 130,41,15,71 \%$ more economical than the most expensive orientation. And finally, if the building orientation of Primitive type is set at $\mathrm{X}=60^{\circ}, \mathrm{Y}=30^{\circ}$ and $\mathrm{Z}=90^{\circ}$, it will cost $\$ 88,62$ being $12,50 \%$ less than the most expensive orientation option.

Machine learning enabled the prediction of the cost and consumption of support material. However, despite the excellent efficiency of all the algorithms used, for the cost prediction, the multiple linear regression algorithm, was the best algorithm of the three studied, due to the perfect cost prediction, obtaining 1 correlation coefficient and 0 mean absolute error. In the support material prediction, all the algorithms were very efficient, but Multi-Layer Perceptron algorithm reached the best result, reaching 0,9983 of correlation coefficient and 0,178 of mean absolute error.

Then, we can conclude that in these experimental conditions the study showed good feasibility to predict the optimized conditions of costs and support material for the studied TPMS. There is a need for further research regarding these same algorithms using other test methods in the WEKA software. 


\section{Declarations}

Funding: This study was financed in part by the Coordenação de Aperfeiçoamento de Pessoal de Nível Superior - Brasil (CAPES) - Finance Code 001.

Conflicts of interest/Competing interests: Not applicable

Availability of data and material: Not applicable

Code availability: Not applicable

Ethics approval: Not applicable

Consent to participate: Not applicable

Consent for publication: Not applicable

Authors' contributions: Not applicable

\section{References}

1. Wong KV, Hernandez A. (2012). A review of additive manufacturing. International scholarly research notices. https://doi.org/10.5402/2012/208760

2. Ngo TD, Kashani A, Imbalzano G, Nguyen KT, Hui D. (2018). Additive manufacturing (3D printing): A review of materials, methods, applications and challenges. Composites Part B: Engineering, 143, 172-196. https://doi.org/10.1016/j.compositesb.2018.02.012

3. Allen S, Dutta D. (1994). On the computation of part orientation using support structures in layered manufacturing. In 1994 International Solid Freeform Fabrication Symposium.

4. Croccolo D, De Agostinis M, Fini S, Olmi G, Vranic A, Ciric-Kostic S. (2016). Influence of the build orientation on the fatigue strength of EOS maraging steel produced by additive metal machine. Fatigue \& Fracture of Engineering Materials \& Structures, 39(5), 637-647. https://doi.org/10.1111/ffe.12395 
5. Alpaydin E. (2020). Introduction to machine learning. MIT press.

6. Mohamed OA, Masood SH, Bhowmik JL. (2017), "Influence of processing parameters on creep and recovery behavior of FDM manufactured part using definitive screening design and ANN", Rapid Prototyping Journal, Vol. 23 No. 6, pp. 998-1010. https://doi.org/10.1108/RPJ-12-2015-0198

7. Mohamed OA, Masood SH, Bhowmik JL. (2016). Investigation of dynamic elastic deformation of parts processed by fused deposition modeling additive manufacturing. Advances in Production Engineering \& Management, 11(3). 227-238. http://dx.doi.org/10.14743/apem2016.3.223

8. Sood AK, Equbal A, Toppo V, Ohdar RK, Mahapatra SS. (2012). An investigation on sliding wear of FDM built parts. CIRP Journal of Manufacturing Science and Technology, 5(1), 48-54. https://doi.org/10.1016/j.cirpj.2011.08.003

9. Jiang J, Hu G, Li X, Xu X, Zheng P, Stringer J. (2019). Analysis and prediction of printable bridge length in fused deposition modelling based on back propagation neural network. Virtual and Physical Prototyping, 14(3), 253-266. https://doi.org/10.1080/17452759.2019.1576010

10. Kapfer SC, Hyde ST, Mecke K, Arns CH, Schröder-Turk GE. (2011). Minimal surface scaffold designs for tissue engineering. Biomaterials, 32(29), 6875-6882. https://doi.org/10.1016/j.biomaterials.2011.06.012

11. Yang SD, Lee HG, Kim J. (2010). A phase-field approach for minimizing the area of triply periodic surfaces with volume constraint. Computer Physics Communications, 181(6), 1037-1046. https://doi.org/10.1016/j.cpc.2010.02.010

12. Maconachie T, Tino R, Lozanovski B, Watson M, Jones A, Pandelidi C, et al. (2020). The compressive behaviour of ABS gyroid lattice structures manufactured by fused deposition modelling. International journal of advanced manufacturing technology, 107(11-12), 4449-4467. https://doi.org/10.1007/s00170-020-05239-4

13. de Aquino DA, Maskery I, Longhitano GA, Jardini AL, del Conte EG. (2020). Investigation of load direction on the compressive strength of additively manufactured triply periodic minimal surface scaffolds. The International Journal of Advanced Manufacturing Technology, 109(3), 771-779. https://doi.org/10.1007/s00170-02005706-y

14. Karimipour-Fard P, Behravesh AH, Jones-Taggart H, Pop-Iliev R, Rizvi G. (2020). Effects of design, porosity and biodegradation on mechanical and morphological properties of additive-manufactured triply periodic minimal surface scaffolds. Journal 
of the Mechanical Behavior of Biomedical Materials, 112, 104064.

https://doi.org/10.1016/j.jmbbm.2020.104064

15. Moleirinho MG, Feast S, Moreira AS, Silva RJ, Alves PM, Carrondo MJ, et al. (2021). 3D-printed ordered bed structures for chromatographic purification of enveloped and non-enveloped viral particles. Separation and Purification Technology, 254, 117681. https://doi.org/10.1016/j.seppur.2020.117681

16. Montgomery DC, Runger GC. (2016). Estatística Aplicada e Probabilidade para Engenheiros. 6a ed. Rio de Janeiro: LTC.

17. Gomes FP. (2000). Curso de estatística experimental. 14. Piracicaba: Universidade de São Paulo.

18. Srivastava M, Rathee S, Maheshwari S, Kundra TK. (2018). Multi-objective optimisation of fused deposition modelling process parameters using RSM and fuzzy logic for build time and support material. International Journal of Rapid Manufacturing, 7(1), 25-42. https://doi.org/10.1504/IJRAPIDM.2018.089727

19. Mwema FM, Akinlabi ET. (2020). Print Resolution and Orientation Strategy. Fused Deposition Modeling. Springer, Cham, pp. 17-32.

20. Molero E, Fernández JJ, Rodríguez-Alabanda O, Guerrero-Vaca G, Romero PE. (2020). Use of Data Mining Techniques for the Prediction of Surface Roughness of Printed Parts in Polylactic Acid (PLA) by Fused Deposition Modeling (FDM): A Practical Application in Frame Glasses Manufacturing. Polymers, 12(4), 840. https://doi.org/10.3390/polym12040840

21. Huynh LP, Nguyen HA, Nguyen HQ, Phan LK, Thanh TT. (2019). Effect of process parameters on mechanical strength of fabricated parts using the fused deposition modelling method. 36 (8). http://doi.org/10.7736/KSPE.2019.36.8.705

22. Barrios JM, Romero PE. (2019). Decision tree methods for predicting surface roughness in fused deposition modeling parts. Materials, 12(16), 2574. https://doi.org/10.3390/ma12162574 
Figures

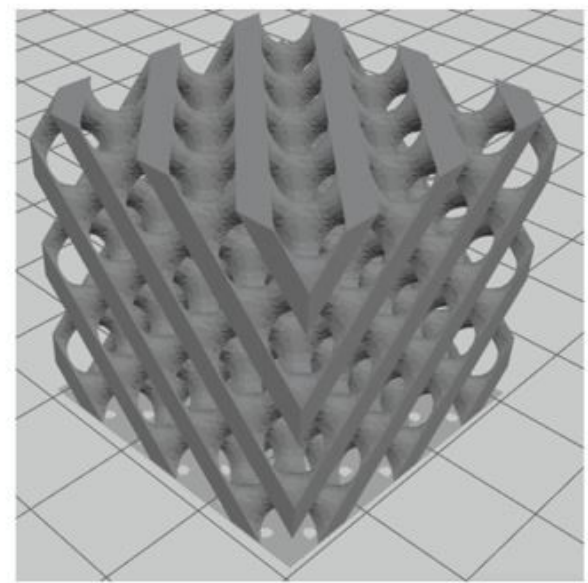

DIAMOND

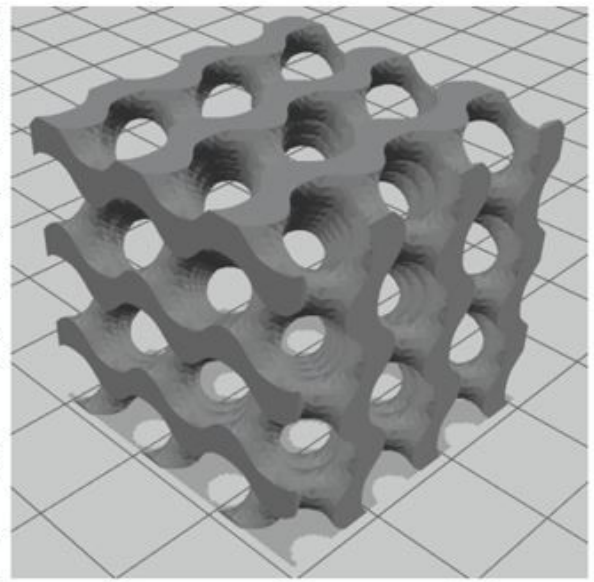

GYROID

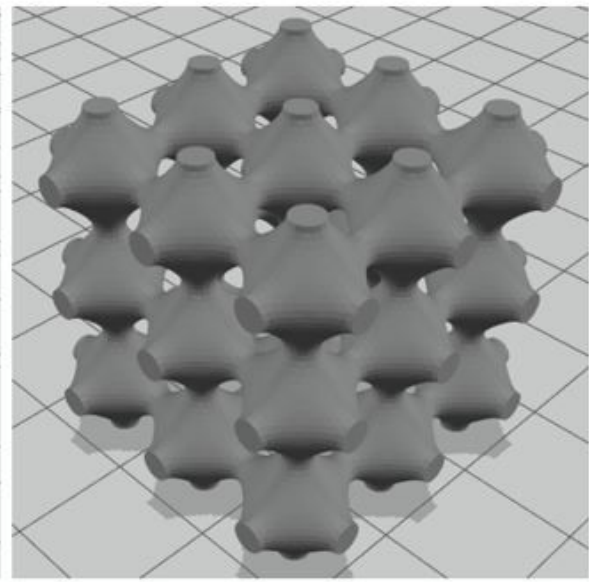

PRIMITIVE

Figure 1

TPMS Source: Author

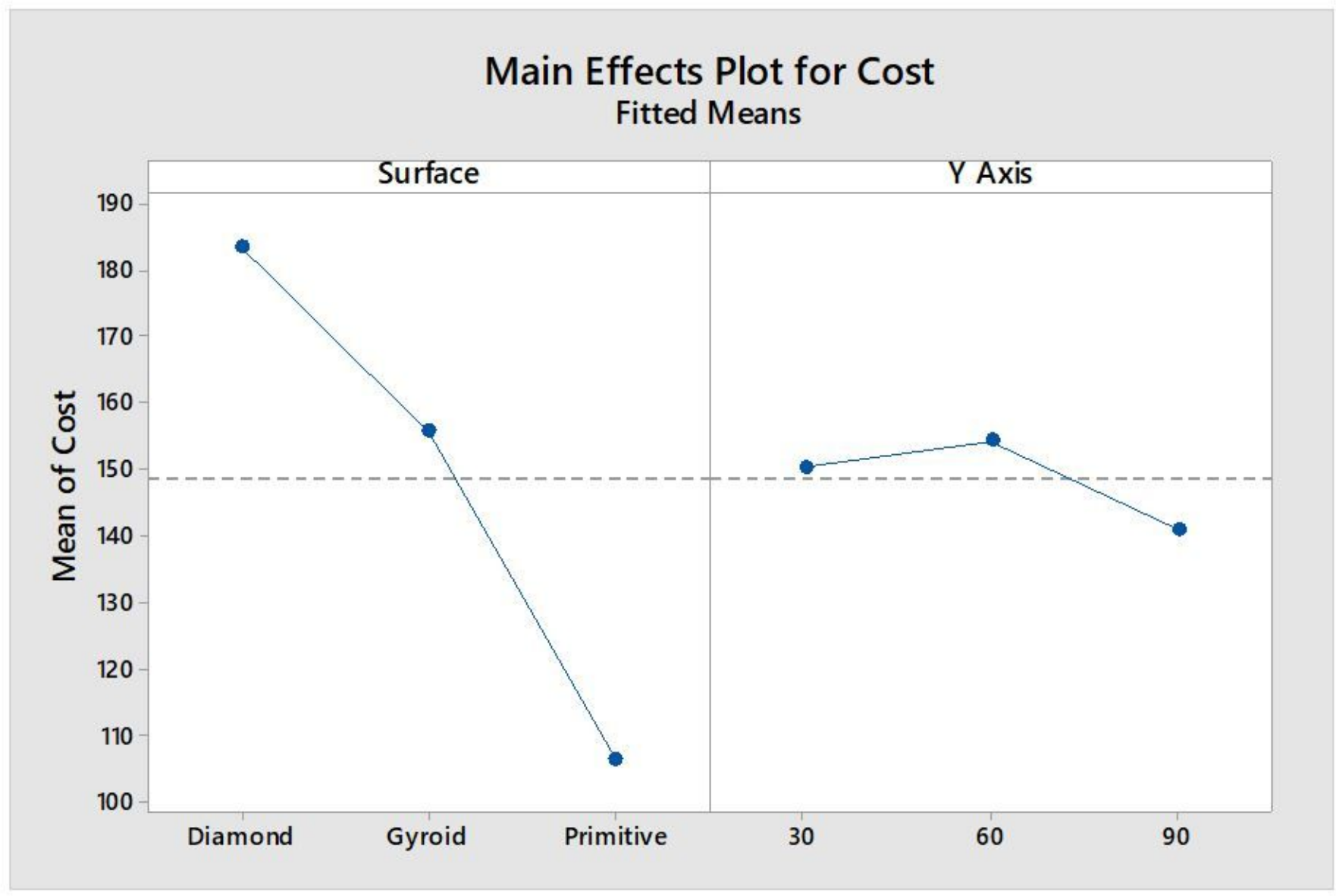


Figure 2

Main effects plot Source: Minitab Analysis Result

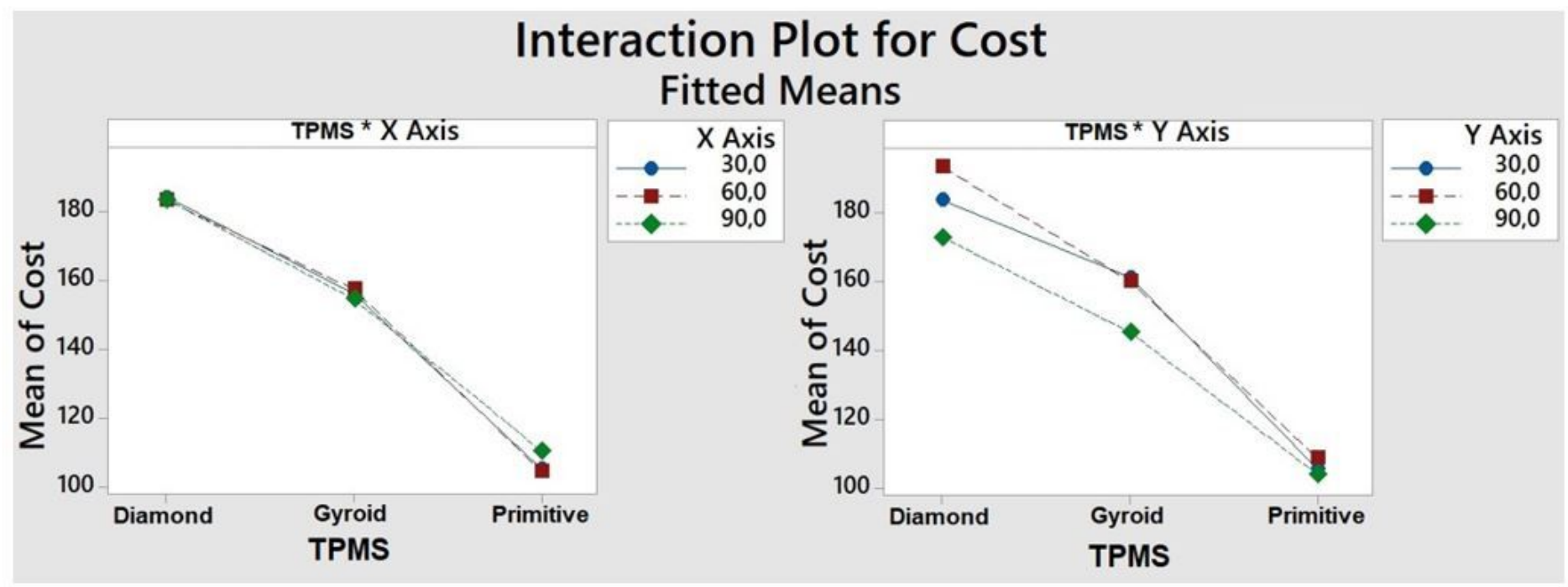

\section{Figure 3}

Interaction plot Source: Minitab Analysis Result

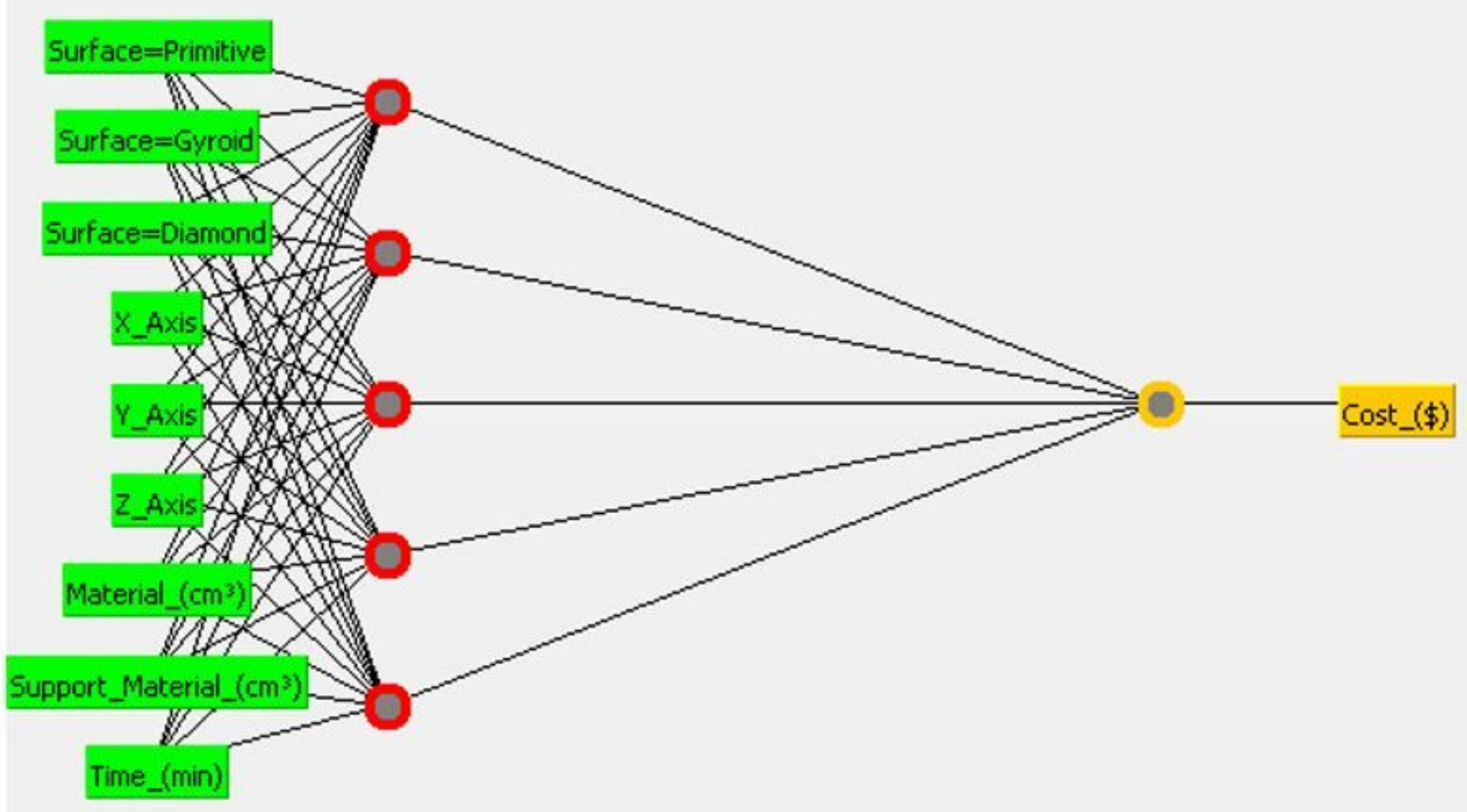

\section{Figure 4}

Neural networks created by the Multilayer Perceptron algorithm for cost Source: Author 


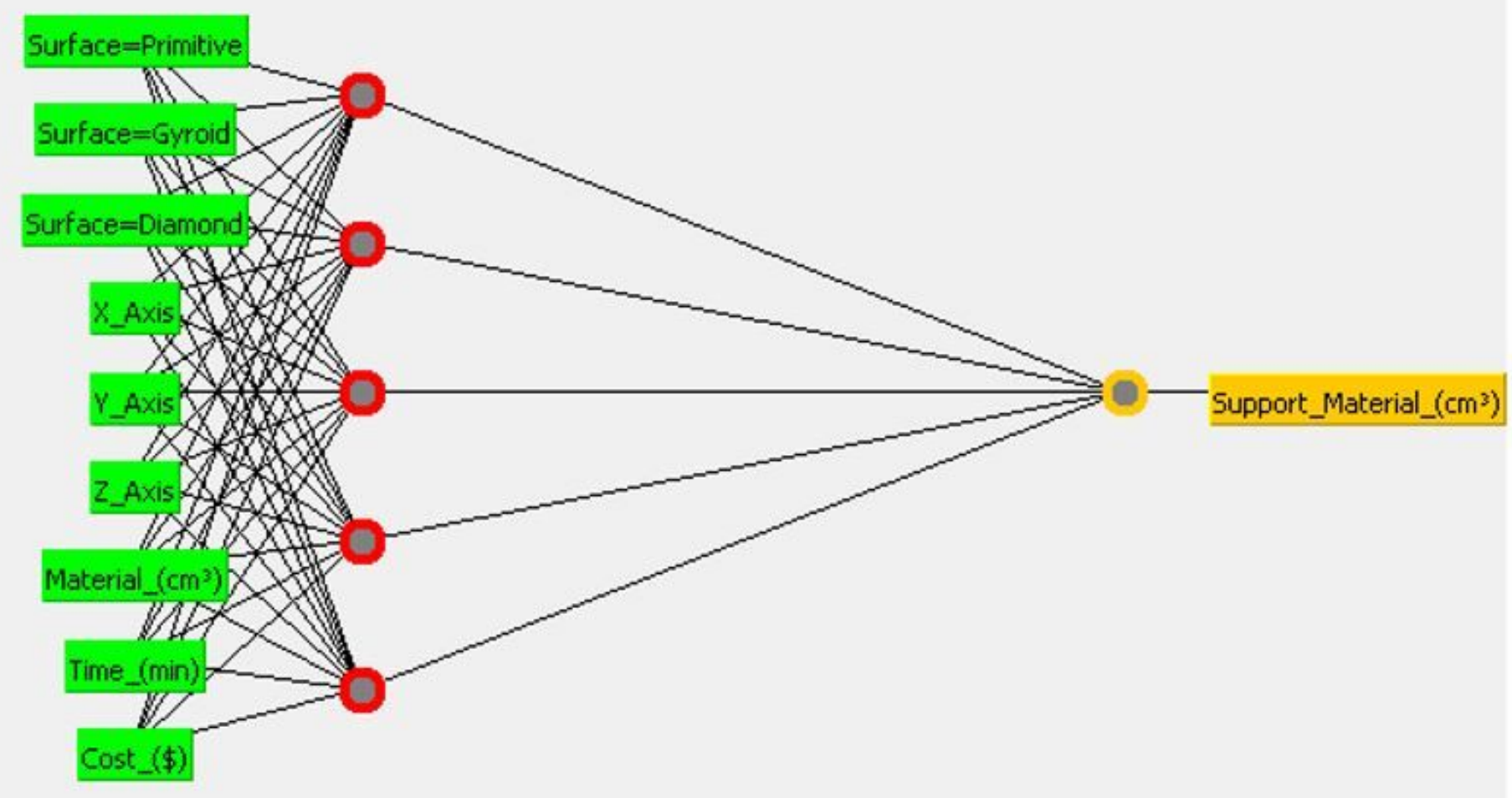

Figure 5

Neural networks created by the Multilayer Perceptron algorithm for support material Source: Author

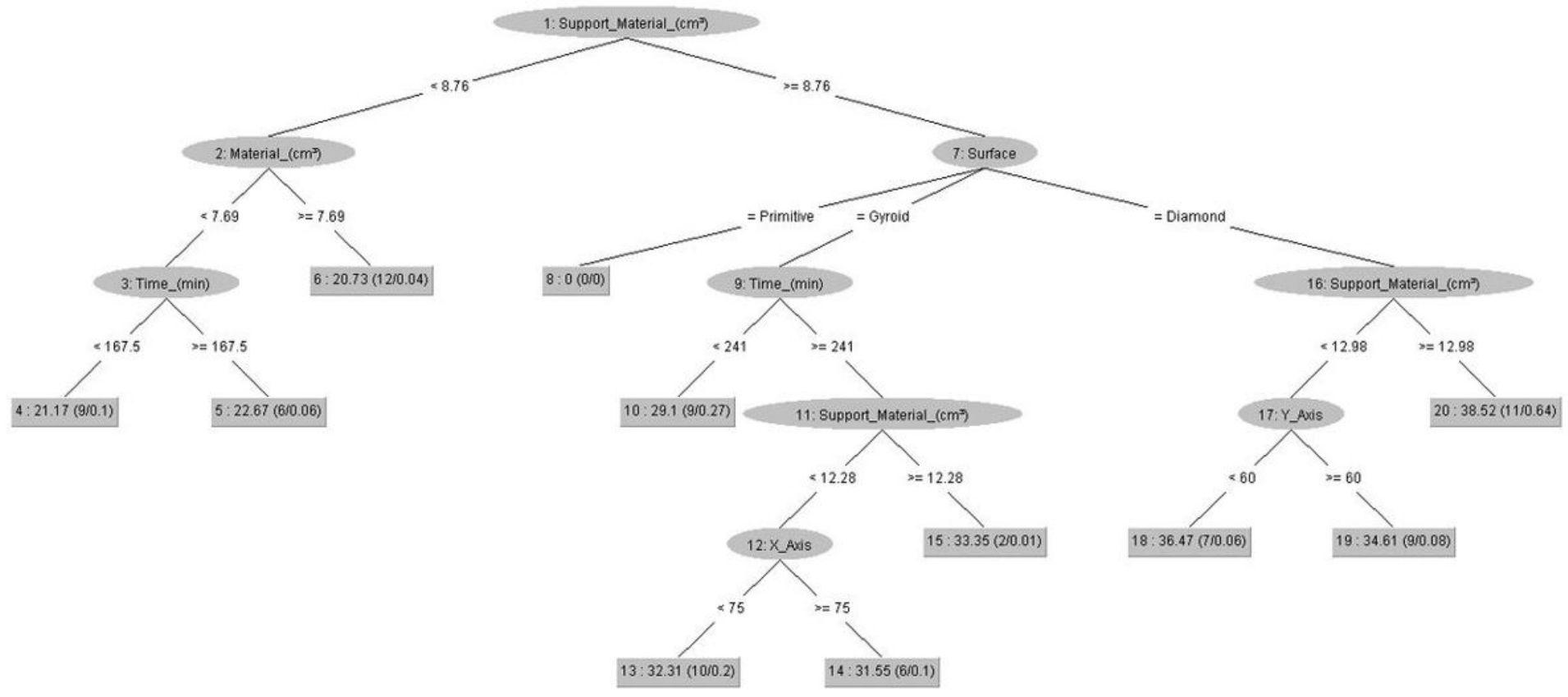

Figure 6 
Decision tree from Random Tree algorithm to predict cost Source: WEKA

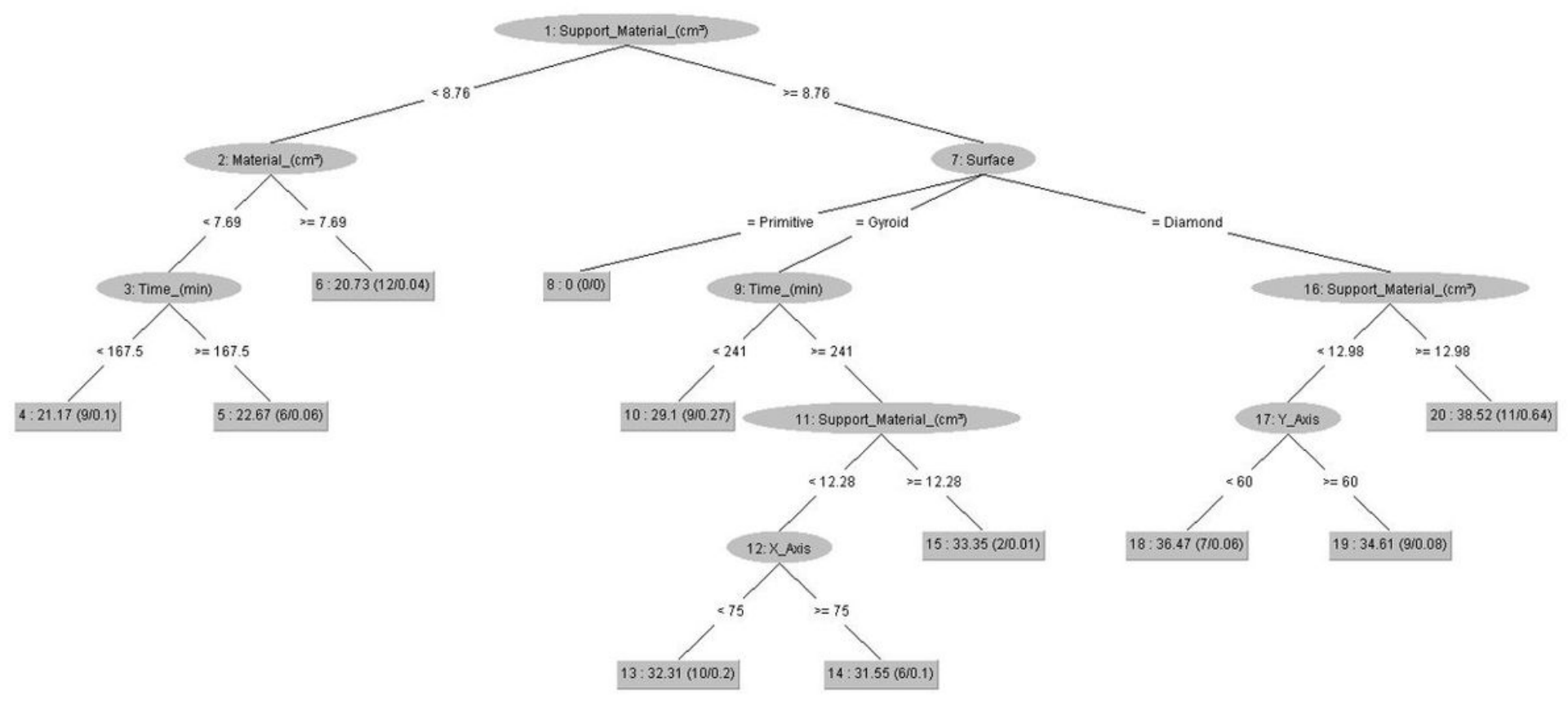

\section{Figure 7}

Decision tree from Random Tree algorithm to predict support material Source: WEKA 